\title{
The Need for Culture Sensitive Participatory Health Promotion Activities To Promote Breastfeeding
}

\author{
Shingirai Katsinde ${ }^{1}$, Sunitha Srinivas ${ }^{1}$ and Diana Hornby ${ }^{2}$ \\ ${ }^{1}$ Faculty of Pharmacy, Rhodes University, Grahamstown, South Africa \\ ${ }^{2}$ Community Engagement Office, Rhodes University, Grahamstown, South Africa
}

\begin{abstract}
Breastfeeding practices are no longer a norm nowadays. Exclusive breastfeeding is an even bigger challenge, and although it is recommended by the World Health Organisation (WHO) that mothers should exclusively breastfeed for the first six months of a baby's life, not many mothers actually practice it. Health promotion activities to promote exclusive breastfeeding are necessary to improve the practices within communities. There is a need to be culturally sensitive when addressing communities as there are already values and beliefs in place that can either promote or hinder the process of health promotion. Community participation is also an important aspect to incorporate during implementation of breastfeeding-promotion activities, because it encourages active participation and is more likely to be accepted than an approach where the community is given information in a directive manner.
\end{abstract}

Keywords: Culture sensitive, health promotion, exclusive breastfeeding, participatory approach.

\section{INTRODUCTION}

In 1978, at the International Conference on primary health care, the urgency for the need to promote and protect the health of all people was articulated. The Alma-Ata Declaration strongly reaffirmed health as a human right, and the implementation of primary health care was required to provide the necessary first level contact health care to the community. ${ }^{1}$ The declaration set a standard to achieve health for all by the year 2000, but as the year 2000 approached, it was clear that the goal could not be attained. In 2000, the 191 United Nations (UN) member states met at the Millennium Summit and developed the Millennium Development Goals (MDGs). ${ }^{2}$

The MDGs were meant to address the social determinants of health i.e. eradication of poverty, promotion of education, gender equality and women empowerment, and ensuring a sustainable environment, as well as health-related issues i.e. child and maternal health, the Human Immuno deficiency Virus/Acquired Immune Deficiency Syndrome (HIV/AIDS), malaria and other diseases as well as global partnerships for development. ${ }^{3,4,5}$ Some of the MDG targets have already been met or are within close reach whilst others require accelerated focus and bolder action so as to make improvements. ${ }^{6}$ Amongst the MDGs that require improvements is the health-related MDG 4, which aims to reduce child mortality. ${ }^{6,7}$

\section{MDG 4: REDUCE CHILD MORTALITY}

MDG 4, target 4a aims to reduce the underfive child mortality by two-thirds between 1990 and 2015., The indicators set to monitor progress at the World Millennium Summit for target $4 \mathrm{a}$ include the under-five mortality rate (UFMR) as well as the infant mortality rate (IMR). ${ }^{10} \mathrm{UFM}$ is the death of a child before age of five, and UFMR is the
Submitted Date : 14-04-2014 Accepted Date : 15-06-2014

DOI: 10.5530/ijopp.7.2.2

Address for correspondence: Sunitha Srinivas M.Pharm, PhD, Associate Professor, Pharmacy Practice Faculty of Pharmacy Rhodes University Grahams town, South Africa +27 46603 8496

E-mail: s.srinivas@ru.ac.za

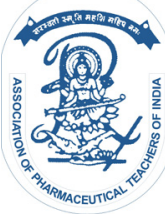

www.ijopp.org 
probability of a child dying per 1,000 live births before reaching the age of five. IM is the death of a child under one year of age and the IMR is the probability of a child dying per 1,000 live births before reaching the age of one. ${ }^{9,10,11}$

The IMR has been reported by the World Health Organisation (WHO) to have decreased globally, from 63 deaths per 1,000 live births in 1990 to 35 deaths in 2012, whilst the overall UFM has decreased from 90 deaths per 1,000 live births to 48 deaths per 1,000 live births. ${ }^{12,13}$ Despite this improvement, the world is unlikely to reach its target of decreasing child mortality by two-thirds by the year 2015 if the current trend in the decrease of mortality continues. ${ }^{7,14-16}$

Sub-Saharan Africa has made slight improvements in the goal to achieve MDG 4, from 177 deaths per 1,000 live births in 1990, to 98 deaths in 2012. In South Africa, the UFMR decreased from 62 deaths per 1,000 live births in 1990, to 47 in 2011 whereas the 2015 target is $20 . \cdot^{17,18}$ According to the South African MDG report of 2013, the UFMR target is likely to be achieved by 2015. The IMR in South Africa has had improvements with a decrease from 54 deaths per 1,000 live births in 1998, to 35 in 2011. ${ }^{10,28}$ According to the South African MDG country report of 2013, the IMR target of 18 is likely to be achieved by the year 2015. Both the IMR and UFMR targets are likely to be achieved following the introduction of the Prevention of Mother to Child Transmission programme (PMTCT) in 2001 and the pneumococcal and rota virus vaccines in April 2009. ${ }^{19-21}$

\section{Causes of infant mortality}

The United Nations Children's Fund (UNICEF) reports that globally, pneumonia, meningitis, tetanus, malaria, pre-term birth complication, intra-partum-related complications and diarrhoea are the leading causes of death among children under the age of five years. ${ }^{19,22}$ In South Africa, the Department of Health, Committee on Morbidity and Mortality in Children under Five Years (CoMMIC) reported that the top five causes of deaths in children were neonatal disorders, diarrhoeal disease, lower respiratory tract infections, HIV/AIDS and severe malnutrition. ${ }^{24}$ Lack of trained health care personnel to provide sufficient information on infant health to the caregivers also affects the rate of infant mortality. ${ }^{25}$

Malnutrition is a major cause of mortality (directly or indirectly) and thus, it is important that nutrition becomes an important aspect that should be emphasized in programmes that involve child and new-born survival. ${ }^{24,27,28}$ Globally, one third of all child deaths are due to malnutrition. ${ }^{28}$ In South Africa, malnutrition resulted in over $6 \%$ of direct causes of under-five infant deaths, and was also a contributing factor in over 50\% of under-five infant deaths in 2005. Optimum nutrition in children under the age of two is critical in child development and growth thus education about nutrition for child guardians and mothers is important. ${ }^{27,28}$ Exclusive breastfeeding is an important aspect of nutrition and has been shown to have a protective effect on infant mortality and morbidity especially in low income settings. ${ }^{29,30}$

\section{Importance of exclusive breastfeeding}

WHO recommends that a baby should be breastfed exclusively for 6 months after birth, which means that an infant only receives breast milk and no additional foods or liquids, not even water, for 6 months. ${ }^{31}$ Early initiation of breastfeeding (within the first hour of birth) reduces the chances of new-born mortality. ${ }^{31,32}$ Exclusive breastfeeding is associated with several benefits for both the mother and the child. Breastfeeding is effective in the prevention of child deaths because breast milk contains the correct amounts of water and essential nutrients that are critical for infant growth and development. ${ }^{32-34}$ Breast milk protects against illnesses as it contains antibodies which also promotes recovery of a sick child. ${ }^{32,34,35}$

Infants under the age of two years who are not breastfed especially within low income communities, are more likely to die from diarrhoea, gastrointestinal infections or respiratory infections than those who are breastfed. ${ }^{24,32,34}$ The breastfeeding process improves the mother and child bonding but poor breastfeeding techniques, especially latching and positioning, are known to predispose women to breast health problems including mastitis, engorgement and cracked nipples. ${ }^{35-37}$ In studies conducted in South Africa and Zambia, women who exclusively breastfed were less likely to experience breast problems than women who did not exclusively breastfeed. ${ }^{33,36-38}$

\section{Exclusive breastfeeding practices in South Africa}

Unfortunately in South Africa, exclusive breastfeeding is no longer regarded as a 'cultural norm' thus most mothers practice mixed feeding i.e. both breast milk and formula feeding. Low exclusive breastfeeding rates, i.e. $12 \%$ in $0-3$ months old infants and $1.5 \%$ in $4-6$ months old infants, were reported by the South African Demographic and Health Survey (SADHS) in 2003. Within the survey, $85 \%$ of the 10,214 households that were targeted for inclusion took part in the survey. ${ }^{27,39}$ Low income communities within South Africa usually lack running tap water. Formula feeding then poses a greater risk to the child due to use of contaminated water in the preparation of the formula milk, thus exposing 
the child to conditions such as diarrhoea which can cause death. Avoiding breastfeeding in such a situation can also lead to malnutrition of the infants as formula feeding is very expensive especially when compared to breastfeeding. ${ }^{28,33,34,40,41}$

In South Africa, some mothers receive counselling on breastfeeding practices from health care professionals within the public sector but the counselling has been shown to be insufficient. ${ }^{42,43}$ Interventions have been employed to provide mothers with additional support at community level, such as peer counselling and support through community health workers, and these have been used successfully to promote exclusive breastfeeding. During these interventions, issues were brought up by the mothers about the challenges and barriers that they experience when breastfeeding, and these will be discussed in the next section. ${ }^{54,55,57}$

\section{Common factors affecting breastfeeding practices in South Africa}

Most mothers when interviewed in the studies done in South Africa acknowledged that they do not breastfeed for several reasons, and the most common ones will be discussed in this section. Women raised their concerns about sore nipples associated with breastfeeding. Some of these women were first-time mothers who had been told by friends or family members that breastfeeding causes sore nipples, whilst others had experienced it before. Weight loss was also an issue that was concerning to the mothers, as most of them said they had read that breastfeeding results in weight loss. Some of the mothers expected to lose weight, but when they did not they stop breastfeeding. Some women were worried that their babies would not be properly nourished by breast milk only and therefore they either decided on their own, or they were encouraged by their mothers, sisters or husbands to add complementary foods to the baby's diet. ${ }^{43-45}$ The influence of the fathers was found to be very substantial, and being the primary support to the breastfeeding mother, has been shown to contribute largely to the decision to either breastfeed or not, thus resulted in most of the mothers agreeing to the decision to add complementary foods. ${ }^{46,47}$

In South Africa, HIV-positive mothers are encouraged by health care professionals to strictly exclusively breastfeed for 6 months. Promotion of exclusive breastfeeding has proven to be difficult for both HIV-positive and HIV-negative mothers because they fear the stigma that is associated with being HIV-positive and exclusively breastfeeding. From the factors listed above, it is clear that most of mothers make a decision to either breastfeed or not without sufficient knowledge on breastfeeding. Studies conducted in South Africa have recommended that promotion of optimal breastfeeding practices is paramount and before breastfeeding promotion programmes are developed, there is need to have a clear understanding of what the women who breastfeed believe and know, as well as what they are actually putting into practice. ${ }^{36,37,41,42,43}$

\section{HEALTH PROMOTION}

The promotion of health was affirmed in the AlmaAta declaration of 1978 when the 'health for all concept' was articulated. The declaration also emphasized that it was the people's duty to participate, whether as an individual or collectively in groups in the planning and implementing of health care plans that suit them. ${ }^{1}$ Health promotion supports personal and community development through the dissemination of information which ultimately increases community capacity and empowerment. ${ }^{47}$ In order to successfully implement health promotion activities, social, spiritual and cultural resources should be harnessed to promote community action and development. ${ }^{48,49}$ Health promotion interventions are appropriate strategies for increasing exclusive breastfeeding practices, and this has been done successfully in different countries. ${ }^{45,48,49,50}$

The health promotion status in most African countries is low. Few of the countries have actually developed health promotion policies and even fewer have implemented one. ${ }^{51,52}$ In South Africa, there exists a Directorate of Health Promotion located within the Social Sector Cluster (SSC) within Primary Health Care (PHC), District and Development operations which falls under the Deputy Director General for Health Service Delivery in the National Department of Health (DoH) in South Africa. ${ }^{51,53}$ This directorate mainly offers support to provincial and local governments which implement health promotion activities but because there are non-governmental organisations (NGOs) who also conduct health promotion activities around the country, there is no single body coordinating activities. It is therefore necessary to establish a well-coordinated monitoring and evaluation infrastructure to support health promotion activities that encompasses both governmental and NGO bodies so that the programmes can take effect. ${ }^{51,52,53}$

Some of the funding for health promotion activities is available from the National Treasury, via the Department of Health (DoH). This is not the only funding available, as agencies such as the United Nations Agencies, bilateral Aid agencies and various foundations support health promotion interventions both technically and financially. ${ }^{51}$ The shortage of human resources is being addressed by some universities within South Africa that offer courses in health promotion, which 
range from short courses, diplomas, bachelor's degrees to master's degrees in health promotion. These courses are meant to develop the knowledge and skills required in health promotion implementation within the country. ${ }^{51,52}$

The WHO Health Promoting Schools Initiative (HPSI) documents were useful in the development of HPS in South Africa. ${ }^{53}$ This initiative is responsible for the implementation of primary school nutrition programmes, school food gardens and the sanitation facilities installed in some schools around the country.,51,52 In 2012, the Integrated School Health Programme was launched by the President in an attempt to maximise the learning capabilities of learners within primary and secondary schools is South Africa through improving their physical, mental and social wellbeing. ${ }^{54}$

\section{Health promotion for exclusive breastfeeding}

WHO and UNICEF (1989) report that health care practices that relate to mothers and their new-born infants stand out as one of the means that increase the duration and prevalence of breastfeeding. ${ }^{55}$ The support to breastfeed provided by health workers can become part of a society's commitment to accept and implement appropriate breastfeeding practices. This is especially crucial in communities in which bottle feeding is prevalent and the elders within the community know little or nothing about breastfeeding. Mothers should be well equipped with information regarding breastfeeding because ultimately, they are the ones who practice it. ${ }^{56}$

\section{Culture in health promotion}

Culture is a system of values and beliefs within a society that have influence on behaviours. Cultural values are some of the causes of health disparities and are associated with health and health-related behaviours. ${ }^{57,58} \mathrm{In}$ order to try and eliminate health disparities, the influence of culture on knowledge, attitudes, beliefs and practices should be acknowledged by public health policymakers as well as health care professionals who are responsible for the provision of health care services to the people. Cultural values are therefore essential in the development of health promotion programmes. ${ }^{57,59}$ The development of such programmes also require the participation of the individuals affected as well the communities that they come from in order to be able to formulate interventions that consider culture. ${ }^{57}$ The concept of using community health workers (CHWs) to reach out to communities in an attempt to bridge the gap between culture and health promotion, has been successfully implemented in some communities. ${ }^{57,58,59}$ CHWs have the advantage that an element of trust has already been established with the community. ${ }^{59}$

\section{Role of culture in breastfeeding}

Breastfeeding practices are a balance of both culture and biology. Problems with breastfeeding can arise when cultural beliefs and practices do not support the biologically based needs of both the mother and the child. Information that is new to the mother can challenge a mother's beliefs such that she can disregard it as it goes against her beliefs. Women in communities therefore rely on society for support and approval to breastfeed. Many at times, mothers and aunts of the women in the child bearing age are considered the models and advisors in relation to breastfeeding information, but some of these models may actually have little information about breastfeeding. ${ }^{60}$ In some communities within central Sahara, Mexico, Iran, Greece, Myanmar and Malaysia, colostrum is/has been considered a harmful substance by the elders and people within those communities such that the mothers will also disregard colostrum within the first days post-partum. ${ }^{56,61}$ In some cultures, breastfeeding mothers cannot be involved in sexual activities as these are believed to affect the milk, and if a baby cries, then the mothers' milk is stale and unsuitable for the child to feed on. . $5,62,63^{-1}$

In low income areas where mothers cannot afford formula milk, it is not a realistic option not to breastfeed especially when main sources of water are ponds or rivers, such that there is inadequate access to clean water. From a study conducted in South Africa, mixed feeding was culturally acceptable in both rural and township settings, although within rural settings where the homes are isolated, exclusive breastfeeding was more likely to be of longer duration. Non-prescribed medicines were found to be administered for cultural and spiritual reasons and this was mostly common if the leaders of the community initiated it. ${ }^{56}$ Some of these medicines were believed to protect the infant and the mother from evil influences e.g. Doepa, Vimbela and Amafuta Enjayolwandla. In a study conducted in the Eastern Cape province of South Africa, between 66\% and $85 \%$ of medicines purchased from 'African chemists' or 'Amayeza stores' were mainly for the protection of infants from evil spirits. ${ }^{64}$ Such locally sensitive issues need to be discussed in breastfeeding programmes as well as when counselling mothers. Breastfeeding programmes also need to include issues such as milk letdown and breast health problems as these are usually considered as culturally based problems thus the need to educate and inform the mothers with the details on how to tackle such issues is pertinent. ${ }^{56}$

\section{Participation in health promotion}

Community participation involves the community in the planning and implementing of health development 
programmes such that the individuals are viewed as participants within, rather than passive recipients of a programme. ${ }^{65}$ The concept of participation was a key principle in the Alma-Ata declaration. ${ }^{1}$ Most of the health programmes that encourage health promotion in South Africa are developed by the NGOs, and the participation of the community within those programmes has been shown to be significant, for instance, the health promotion policy. ${ }^{51}$ This policy was built on four approaches, community participation and reorientation of health services, the setting approach, education and information as well as policy, advocacy and health environments. ${ }^{54}$ The participatory approach has principles that include enabling empowerment of the participants themselves, in realising that they need to take charge of their own health, be self-aware and that their ideas and desires are also important in the development of health promotion programmes. ${ }^{66}$

Recently, the individuals who are involved in health and development programmes started using a new approach to health promotion. They began to act as facilitators who support the local communities to become active participants in the development and decision making processes that evolve around health promotion. ${ }^{67}$ Successful national health programmes in which the com- munity participation approach was used, were reported in China, Cuba, Tanzania and Sri Lanka. In Western Kenya and the state of Maharashtra in India, smaller scale sub-national pilot programmes that implemented such health projects showed evidence of drastic effects within the community. However, these same projects could not be easily replicated on a larger scale because once it became a national programme, bureaucratic rules and top-down directives changed the nature of community participation, which then hurried the process necessary for engagement with the communities. ${ }^{66,67} \mathrm{It}$ is therefore necessary for the implementation of health promotion that encourages participation, makes use of the bottoms up approach (active participants), rather than the top-down approach (passive recipients). ${ }^{65}$

\section{Theoretical model: PEN-3 model}

The PEN-3 model was developed in 1989 by Professor Collins O. Airhihenbuwa from Pennsylvania State University, as a strategy to address the impact of culture on health-related behaviour and decision making. ${ }^{68,69}$ The PEN-3 model comprises three interlinked dimensions which are dependent on each other: cultural identity, relationships and expectations, and cultural empowerment (see Figure 1 below) ${ }^{68-70}$

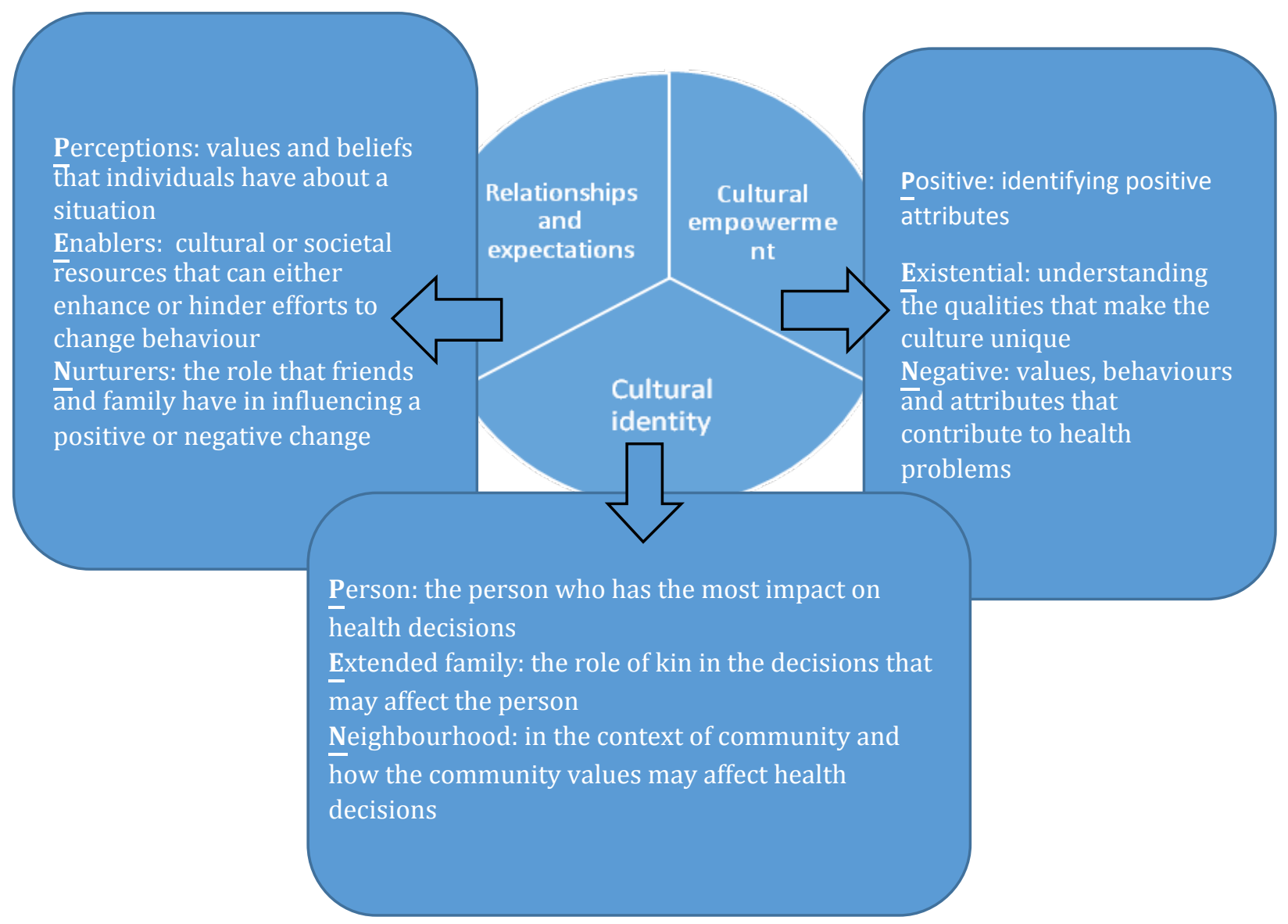

Figure 1: The PEN-3 model 
Cultural identity: identifies and defines the target audience, i.e. either the person, the extended family or the neighbourhood in which they live. The target audience have to change their health-related behaviour and this serves as the point through which the intervention will be initiated. Relationships and expectations: this dimension is made up of three domains, which have a huge impact in the influence of the target audience.

Cultural empowerment: this dimension is important in the development of interventions that are culturally sensitive by noting the different positive, existential and negative values and behaviours within a community, which actually influence health-related decision making processes. ${ }^{69-71}$

The concept focuses on magnification of cultural issues and their importance for the people who want to address health issues as well as health promotion. ${ }^{68}$ Since this framework provides a cultural framework to researchers that enables them to partner up with the communities when addressing health problems, researchers and the communities involved are able to seek solutions together. ${ }^{68,69,70}$ This model has been used widely and successfully to address issues relating to hypertension, cancer, diabetes, smoking and food choices as well as obesity, and can be useful in addressing health promotion issues. ${ }^{68,69,71}$

\section{CONCLUSION}

The MDGs provide a set of goals for advances to be made globally with respect to different aspects, which are indirectly or directly linked to health. Child and maternal health are indicators of global progress on health. Most child deaths in the world are from preventable causes, especially diarrhoea, pneumonia and malnutrition. Reports suggest that if the few interventions that are available were fully implemented, most of the preventable child deaths could be prevented. Breastfeeding has been found to positively influence child health. WHO recommends that a child be breastfed exclusively for the first six months of their life, but this is no longer a norm in South Africa. This is mainly because most mothers decide to either breastfeed or not, without sufficient knowledge on breastfeeding. The promotion of breastfeeding and exclusive breastfeeding practices in low-income communities has been shown to be of utmost importance with drastic positive effects on child health. Health promotion activities are difficult to implement successfully if there is no behavioural change and culture sensitivity. These two aspects influence the acceptance of health promotion activities. It is therefore crucial that health workers and communities are involved in the health promotion activities that are culturally sensitive and which also take into consideration the views and opinions of the communities into which the activities will be implemented. Community based participatory action is a requirement to enhance the sustainability and to also ensure accountability of activities.

\section{CONFLICTS OF INTEREST}

None.

\section{REFERENCES}

1. International conference on Primary Health Care. Declaration of AlmaAta [online]. 1978 [cited 2014 Feb 19]. Available from : http://www.who.int/ publications/almaata_declaration_en.pdf?ua=1

2. World Health Organization. Millennium development goals. [Online].No date [updated 2013; cited 2013 Nov 25]. Available from: http://www.who.int/topics/ millennium_development_goals/about/en/index.html

3. Marmot M. Social determinants of health inequalities. The Lancet . 2005; 365(9464): 1099-4.

4. World Health Organisation. Health impact assessment. The determinants of health [online]. 2014 [cited 2014 Feb 22]. Available from: http://www.who.int/ hia/evidence/doh/en/

5. United Nations Millennium Declaration. United Nation General Assembly [online]. 2000 [updated 2000; cited 2014 Feb 19]. Available from http://www. un.org/millennium/declaration/ares552e.pdf

6. United Nations. The Millennium Development Goals Report 2013 [online]. 2013 [cited 2014 Mar 08]. Available from: http://www.un.org/millenniumgoals/ pdf/report-2013/mdg-report-2013-english.pdf

7. Health in the post-2015 agenda. Report on the global thematic consultation on health. [Online]. 2013[updated 2013 Apr; cited 2013 Nov 25]. Available from: http://bit.ly/Yg9oMl

8. The World Health Organization. MDG 4: Reduce child mortality. [Online]. [Updated 2013; cited 2013 Nov 21]. Available from: http://www.who.int/ topics/millennium_development_goals/child_mortality/en/index.html

9. United Nations statistics division. Millennium development goals indicators [online]. No date [cited 2014 Feb 26]. Available from: http://mdgs.un.org/ unsd/mdg/Metadata. aspx? Indicatorld=0\&Series $/ \mathrm{d}=562$

10. United Nations statistics division. Millennium development goals indicators .Official list of indicators [online]. No date [cited 2014 Mar 07]. Available from: http://mdgs.un.org/unsd/mdg/Host.aspx?Content=Indicators/OfficialList.htm

11. World health organisation. Life expectancy [online]. No date [cited 2014 mar 07]. Available from: http://www.who.int/whosis/ whostat2006DefinitionsAndMetadata.pdf?ua=1

12. World Health Organisation. Global health observatory data repository [online]. 2013 [cited 2014 Feb 26]. Available from: http://apps.who.int/gho/ data/view.main.182?lang=en

13. World Health Organisation. Levels \& Trends in Child Mortality, 2013 report [online]. 2013 [cited 2014 Feb 26]. Available from:http://www.who.int/ maternal_child_adolescent/documents/levels_trends_child_mortality_2013. pdf?ua=1

14. The World Health Organization. Media center: Millennium development goals. [online]. [updated 2013; cited 2013 Nov 25]. Available from: http:// www.who.int/mediacentre/factsheets/fs290/en/index.html

15. United Nations. The Millennium Development Goals report. New York. 2013 [Online]. [cited 2013 Nov 21]. Available from: http://www.un.org/ millenniumgoals/pdf/report-2013/mdg-report-2013-english. pdf

16. World Health Organisation. Global under-five mortality trend [image on online]. [updated 2013 Sep 13; [cited 2014 Feb 26]. Available from: http:// www.who.int/gho/child_health/child_health_001.jpg?ua=1

17. Countdown to 2015. Maternal, Newborn \& Child Survival. Country profiles [online].2013 May [cited 2014 Feb 27] Available from: http://www. countdown2015mnch.org/documents/2013Report/Countdown_2013Update_profilesS-Z.pdf 
18. Bhutta ZA, Chopra M, Axelson H, et al. Countdown to 2015 decade report (2000-10): Taking stock of maternal newborn and child survival. Lancet. 2010; 375(9730): 2032-44.

19. Statistics South Africa. Millennium development goals. Country report 2013 [online]. 2013 [cited 2014 Feb 28]. Available from: http://beta2.statssa.gov. za/wp-content/uploads/2013/10/MDG_October-2013.pdf

20. Madhi S, Bamford L, Ngcobo N. Effectiveness of pneumococcal conjugate vaccine and rotavirus vaccine introduction into the South African public immunisation programme. S Afr Med J. 2014; 104(3): 228-34.

21. Anova health institute. Prevention of Mother to Child Transmission (PMTCT) [online]. 2014 [cited 2014 Mar 11]. Available from: http://www.anovahealth. co.za/programmes/entry/prevention_of_mother_to_child_transmission_ pmtct/

22. United Nations Children's Fund. Levels \& Trends in Child Mortality. Report 2012 [online]. 2012 [cited 2014 mar 08]. Available from: http://www.unicef. org/videoaudio/PDFs/UNICEF_2012_child_mortality_for_web_0904.pdf

23. Jamieson L, Bray R, Viviers A, Lake L, Pendlebury S, Smith C (eds) (2011) South African Child Gauge 2010/2011.Cape Town: Children's Institute, University of Cape town.

24. Interim REPORT OF THE COMMITTEE ON MORBIDITY AND MORTALITY IN CHILDREN UNDER 5 YEARS (COMMIC) [online]. No date [cited 2014 Mar 08]. Available from: http://www.health.gov.za/docs/reports/2013/ morbidity_\&_mortality.pdf

25. Gonzalez LL. Baby's death sparks national campaign to fix the Eastern Cape. Health -e. The South African health news service [online]. 2013 Sep [cited 2013 Nov 22]. Available from: http://www.health-e.org.za/2013/09/11/ one-baby-national-campaign/

26. Cooke M, Nel E, Cotton M. Pre-hospital management and risk factors in children with acute diarrhoea admitted to a short-stay ward in an urban South African hospital with a high HIV burden. S Afr J CH. 2013; 7(3): 84-7.

27. Fewtrell MS, Morgan JB, Duggan C, Gunnlaugsson G, Hibberd PL, Lucas A, et al. Optimal duration of exclusive breastfeeding: what is the evidence to support current recommendations? The Am J Clin Nutr. 2007 February 01; 85(2): 635S-8.

28. WHO Collaborative study team on the role of breastfeeding on the prevention on infant mortality, effect of breastfeeding on infant and child mortality due to infectious diseases in less developed countries: a pooled analysis. The Lancet. 2000; 355: 451-5

29. Bahl R, Frost C, Kirkwood BR, et al. Infant feeding patterns and risks of death and hospitalization in the first half of infancy: multicenter cohort study. Bull World Health Organ. 2005 ; 83(6): 418-26.

30. Al Juaid DA, Binns CW, Giglia RC. Breastfeeding in Saudi Arabia: a review. Int Breastfeed J 2014 Jan 14; 9(1): 1-4358-9-1.

31. World Health Organization. Infant and young child feeding [online]. [Updated September 2013; cited 22 November 2013]. Available from: http://www.who. int/mediacentre/factsheets/fs342/en/

32. Doherty T, Sanders D, Jackson D, Swanevelder S, Lombard C, Zembe W, et al. Early cessation of breastfeeding amongst women in South Africa: an area needing urgent attention to improve child health. BMC paediatrics. 2012; 12(1): 105.

33. The Partnership for Maternal, Newborn \& Child Health. Essential interventions, commodities and guidelines for reproductive maternal Newborn and Child health [online]. 2011[cited 2013 Nov 25]. Available from: http://www.who.int/ pmnch/topics/part_publications/essential_interventions_18_01_2012.pdf

34. Alive and thrive. Exclusive breastfeeding [online].No date [Cited 22 November 2013]. Available from: http://www.aliveandthrive.org/our-focusareas/exclusive

35. La Leche league International. Can breastfeeding prevent illness [online]. 2008-2013[updated 2012 May 23; cited 2014 Mar 11]. Available from: https://www.llli.org/faq/prevention.html

36. Tylleskar $\mathrm{T}$, Jackson $\mathrm{D}$, Meda $\mathrm{N}$, et al. exclusive breastfeeding promotion by peer counsellors in sub-Saharan (PROMISE-EBF): a cluster-randomized trial. Lancet. 2011; 378: 420-7.

37. Bland RM, Becquet R, Rollins NC, et al: breast health problems are rare in both HIV-infected and HIV-uninfected women who receive counselling and support for breastfeeding in South Africa. Clin Infect Dis. 2007; 45(11): 1502-10.

38. Semrau K, Kuhn L,Brooks DR, Cabral H, Sinkala M, Kankasa C, Thea DM, Aldrovandi GM. Exclusive breastfeeding, maternal HIV disease and the risk of clinical pathology in HIV-infected, breastfeeding women. Am J Obstet Gynecol. 2011; 205(4): 344.

39. Data first. South Africa - Demographic and Health Survey 2003-2004, South Africa [online]. [updated Oct 25; cited 2014 Mar 11]. Available : http://www. datafirst.uct.ac.za/dataportal/index.php/catalog/447/study-description

40. Chopra M, Doherty T, Jackson D, Ashworth A. Preventing HIV transmission to children: quality of counselling of mothers in South Africa. Acta Paediatr. 2005; 94(3): 357-63.

41. Daniels K, Nor B, Jackson D, Eksrtom EV, Doherty T. supervision of community peer counsellors for infant feeding in South Africa: an exploratory qualitative study. Human resources for health. 2010; 8: 6.

42. Journal of human lactation. Beliefs, Attitudes, and Practices of Breastfeeding Mothers from a Periurban community in South Africa [online]. Available from: http://jhl.sagepub.com/content/21/1/31.full.pdf+html

43. Bland R, Rollins N, Coutsoudis A, Coovadia H. Breastfeeding practices in an area of high HIV prevalence in rural South Africa. Acta Paediatr. 2002; 91(6): 704-11.

44. Swanson V, Power KG. Initiation and continuation of breastfeeding: theory of planned behaviour. J Adv Nurs. 2005; 50(3): 27282

45. Campbell $\mathrm{H}$, Jones I. Promoting breastfeeding: a view of the current position and a proposed agenda for action in Scotland. J Public Health Med. 1996 Dec; 18(4): 406-14.

46. Scott JA, Binns CW, Oddy WH, Graham KI. Predictors of breastfeeding duration: evidence from a cohort study. Pediatr. 2006; 117(4): e646-55.

47. Ahuızı R. Knowledge and Practice of Exclusive Breast Feeding: Effects of Health Promotion Intervention in Nigeria. TAF Preventive Medicine Bulletin. 2011; 10(6): 657-64.

48. Nankunda J, Tumwine JK, Nankabirwa V, Tylleskär T. Promise-ebf Study Group. She would sit with me": mothers' experiences of individual peer support for exclusive breastfeeding in Uganda. Int Breastfeed J. 2010; 5: 16.

49. Bhandari N, Bahl R, Mazumdar S, Martines J, Black RE, Bhan MK. Effect of community-based promotion of exclusive breastfeeding on diarrhoeal illness and growth: a cluster randomised controlled trial. The Lancet. 2003; 361(9367): 1418-23.

50. Tylleskär T, Jackson D, Meda N, Engebretsen IMS, Chopra M, Diallo AH, et al. Exclusive breastfeeding promotion by peer counsellors in sub-Saharan Africa (PROMISE-EBF): a cluster-randomised trial. The Lancet. 2011; 378(9789): 420-7.

51. Onya H. Health promotion in South Africa. Promot Educ. 2007; 14(4): 233-7.

52. Sanders D, Stern R, Struthers P, Ngulube TJ, Onya $H$. What is needed for health promotion in Africa: band-aid, live aid or real change? Critical Public Health. 2008; 18(4): 509-19.

53. Department of basic education. Republic of South Africa. Health promotion[online]. 2014 [cited 2014 Apr 03]. Available from: http://www. education.gov.za/Programmes/HealthPromotion/tabid/867/Default.aspx

54. Department of Basic Education. Integrated School Health Programme[online]. 2012 [cited 2014 Apr 04]. Available from: http://www.education.gov.za/ LinkClick.aspx? fileticket $=x 7$ XUJxMcfvs $\% 3 d \&$ tabid $=870 \&$ mid $=2453$

55. World Health Organisation. Geneva. Protecting, promoting and supporting breast-feeding: the special role of maternity services. A joint WHO/UNICEF statement[online]. 1989 [cited 2014 Apr 01]. Available from: http://whqlibdoc. who.int/publications/9241561300.pdf?ua=1

56. Bland R, Rollins N, Coutsoudis A, Coovadia H. Breastfeeding practices in an area of high HIV prevalence in rural South Africa. Acta Paediatr. 2002; 91(6): 704-11.

57. Kreuter MW, McClure SM. The role of culture in health communication. Annu Rev Public Health. 2004; 25: 439-55.

58. Brach C, Fraserirector I. Can cultural competency reduce racial and ethnic health disparities? A review and conceptual model. Medical Care Research and Review. 2000; 57(4): 181-217.

59. Tengland P. Behavior Change or Empowerment: On the Ethics of HealthPromotion Strategies. Public health ethics. 2012; 5(2) 140-53.

60. Mojab CG. The cultural art of breastfeeding. Leaven. 2000; 36: 87-91.

61. Wells J. The role of cultural factors in human breastfeeding: adaptive behaviour or biopower. J Hum Ecol. 2006; 14: 39-47.

62. Beliefs, Attitudes, and Practices of Breastfeeding Mothers from a Periurban Community in South Africa. J Hum Lact February. 2005; 21(1): 31-8.

63. Sibeko L, Dhansay MA, Charlton KE, Johns T, Gray-Donald K. Beliefs, attitudes, and practices of breastfeeding mothers from a periurban community in South Africa. J Hum Lact. 2005 Feb; 21(1): 31-8. 
64. Cocks M, Moller V. Use of indigenous and indigenized medicines to enhance personal well-being: a South African case study[online].no date [cited 2014 Apr 01]. Available from: http://eprints.ru.ac.za/456/1/Use_of_indigenous_ and_indigenised_medicines_to_enhance_personal_well-being_-_a_South_ African_case_study.pdf

65. Bhuyan KK. Health promotion through self-care and community participation: Elements of a proposed programme in the developing countries. BMC Public Health. 2004; 4(1): 11-2

66. Mullan F, Epstein L. Community oriented primary care: new relevance in the changing world. Am J Public health. 2002. 92(11): 1748-55.

67. Rosato M, Laverack G, Grabman LH et al. Alma-Ata: Rebirth and Revision 5 Community participation: lessons for maternal, newborn, and child health. The Lancet. 2008; 372(9642): 962-71.
68. Airhihenbuwa CO, Kumanyika S, Agurs TD, Lowe A. Perceptions and beliefs about exercise, rest, and health among African-Americans. American Journal of Health Promotion. 1995; 9(6): 426-9.

69. Airhihenbuwa C, Okoror T, Shefer T, et al. Stigma, culture, and HIV and AIDS in the Western Cape, South Africa: An application of the PEN-3 cultural model for community-based research. J Black Psychol. 2009; 35(4): 407-32.

70. Melancon J, Oomen-Early J, del Rincon LM. Using the PEN-3 Model to Assess Knowledge, Attitudes, and Beliefs about Diabetes Type 2 among Mexican American and Mexican Native Men and Women in North Texas. Int Electron J Health Educ. 2009; 12: 203-21.

71. Daglas M, Antoniou E. Cultural views and practices related to breastfeeding. Health Sci J. 2012; 6(2): 